\title{
Creative Engagement of Digital Learners with Gardner's Bodily-Kinesthetic Intelligence to Enhance Their Critical Thinking
}

\author{
Charles Kivunja \\ School of Education, The University of New England, Armidale, Australia \\ Email: ckivunja@une.edu.au
}

Received 18 March 2015; accepted 10 April 2015; published 17 April 2015

Copyright (C) 2015 by author and Scientific Research Publishing Inc. This work is licensed under the Creative Commons Attribution International License (CC BY). http://creativecommons.org/licenses/by/4.0/

\section{(c) (i) Open Access}

\begin{abstract}
Although we owe a debt of gratitude to Howard Gardner for articulating in 1983 that all human beings have many intelligences, the recognition that there is a multiplicity of intelligences (MI) among humans and that some are more endowed with and have greater dexterity in some of the intelligences than that in others is nearly as old as mankind. It is well understood that critical thinking is essential for success in all human endeavors. Unfortunately, critical thinking is not explicitly taught in most learning contexts. This paper is guided by the cognitive principle that teaching that aligns with the learner's stronger intelligences and learning style can facilitate active learning and critical thinking. This is a strong pedagogical reason for us as pedagogues with the privilege of training teachers, to make sure that our students adopt this cognitive principle to facilitate learning among all their students-not just those gifted in the orthodoxy skills of language and logic. This paper uses the example of Gardner's bodily-kinesthetic MI to illustrate how trainee and practising teachers can apply some of the latest digital technologies to mobilize the MI of digital students endowed with the bodily-kinesthetic MI to enhance their active learning and critical thinking.
\end{abstract}

\section{Keywords}

Student Engagement, Aligning Teaching to Intelligence, Bodily-Kinesthetic MI, Cognitive Principle, Critical Thinking, Digital Natives 


\section{Introduction}

One of the most outstanding giants in the field of human competences is Harvard University psychologist Professor Gardner (1983, 1999, 2006) who labeled alternative ways of knowing as human multiple intelligences (MI). He defined such intelligences as "The ability to solve problems that one encounters in real life; the ability to generate new problems to solve and the ability to make something or offer a service that is valued within one’s culture” (Christensen, 2011: pp. 25-26). Although we owe a debt of gratitude to Gardner (1983, 2006) for articulating that all human beings have at least nine forms of intelligences, the recognition that there is a multiplicity of intelligences (MI) among humans and that some are more endowed with and have greater dexterity in some of the intelligences than in others is nearly as old as mankind. For example, some 2600 years BCE Egyptian pharaohs looked for what they called "ingenious builders" to design plans for the pyramids. The Greek philosopher Plato (428-348 BCE) called for the shrewdest men to identify precious metals for the Greek Empire. The Roman general Julius Caesar (100-44 BCE) promoted to high ranks only men that he considered to be endowed with what he often referred to as strategic genius and critical thinkers to help him expand the Roman Empire. But early scholars of intelligence reduced it to a unitary number. So it was no wonder that the French modernized the search for intelligence with Intelligence Tests which yielded an individual's intelligence quotient, or IQ, at the dawn of the last century. In spite of some robust and democratic disagreement about the existence and nature of MIs (e.g. White, 2006), we can say, thanks to Gardner and to many brain research scientists and psychologists who have contributed to our understanding, we now know that no two of our students have an identical regimen of intelligences. Gardner's (2006) regimen of now nine comprises the following MIs:

1) Bodily-kinesthetic. This is the ability to develop and use personal physical skills. This intelligence is well demonstrated by the best of athletes in their chosen sport such as Australian Greg Norman and American Tiger Woods in golf; Roger Federer and the William sisters in tennis or Angelina Jolie in movies.

2) Logical-mathematical. Ability to work with numbers as in mathematics, statistics, econometrics and physics and to develop propositions and hypotheses and carry out complex quantitative calculations. Examples of people who demonstrated such intelligence at high levels include Albert Einstein and recent Nobel Prize winner in physics, the late Doris Lessing.

3) Interpersonal. Ability to understand and interact effectively with other people to develop a shared view or vision. Examples of people with exceptional levels of such intelligence include the world renowned Nelson Mandela, Mahatma Gandhi and Mother Teresa.

4) Linguistic. Ability to use language to express deep meanings. Examples include the great orators of the Roman Empire such as Mark Anthony, Shakespeare, Julius Nyerere of Tanzania and Walt Whitman.

5) Naturalist. Ability to work with nature, observe and classify objects into taxonomies that facilitate an understanding of natural and man-made systems. Taxonomist Charles Darwin, and the late Australian Crocodile Hunter Steve Irwin were good examples of persons with this intelligence.

6) Intrapersonal. Ability to develop a realistic self-perception and apply oneself accordingly. Famous thinkers such as Sigmund Freud and Aristotle exemplify this intelligence.

7) Musical. Ability to create music, pitch, melody, rhythm and tone and to compose songs. Mozart, Stevie Wonder, Madonna, Prince, Michael Jackson, Elton John and Kylie Minougue highlight exemplars of abundance of this intelligence.

8) Spatial. Having masterly of imagery. Ability to think in three-dimensional ways and design, transform or modify images. Examples of people with this intelligence include Frank Lloyd Wright and Galileo Galilei.

9) Existential. Ability to tackle the most fundamental questions about human existence. Examples of people include Charles Darwin, Martin Luther King, Nelson Mandela.

So, while the jury is still out as to whether all these categories are necessary (Schaler, 2006), and asking why we can't group them into fewer categories (Sternberg, 1985) or whether these are the only intelligences that exist, or whether in fact there are other types of intelligence (Goleman, 2006) we know that there is a convergence of scholarly opinion that "understanding can come more easily and with greater enthusiasm, when an educational approach is well aligned with one's stronger intelligences” (Christensen, 2011: p. 27). We also know from the work on learning styles by many leaders in the filed (including Cassidy, 2004; Dunn \& Dunn, 1978; Entwistle, 1981; Hartman, 1995; Honey \& Mumford, 1982), that no two children learn the same way. There are therefore strong pedagogical reasons for us as higher education trainers of teachers, to make sure that our graduates are fully aware that if they recognize the existence of multiple intelligences and differences in learning styles in any class they teach, and try to cater for them, they will increase their ability to facilitate learning to personal bests 
for all students-not just those gifted in language and logic, as seems to be the case with the usual emphasis on the traditional 3Rs of reading, -rithmentic and -riting. With the ubiquitous advance of Information Communication Technologies (ICT) our graduates now have tremendous opportunities to access information, store it, share it, process it, edit it, select what they want, present it and communicate information through a wide range of media, including social media (Kivunja, 2013a). As Wegerif (2002) has indicated, "using ICT in classrooms, particularly in a constructivist approach, has great potential to develop students' higher-order cognitive skills” (p. 62). And as Kivunja (2015) demonstrated, the use of social media technologies can significantly increase students' participation and engagement with their learning activities and assessment tasks. Therefore, properly skilled, our graduates should be able to utilize state-of-the-art technologies in their teaching in constructivist classrooms to help children construct understanding in critical thinking ways.

Unfortunately, not many curriculum documents include the teaching of critical thinking as an explicit key learning area or distinct subject (Pithers \& Soden, 2000). Furthermore, some people have argued that the exposure of children to digital technologies has bred a click-click-and-go attitude among children of the digital generation and that such children are less inclined to engage in deep critical thinking because "students today can't read the way students did 20 years ago, ... all they want is play their videogames, ... they just can't concentrate the way kids used to” (Prensky, 2010: p. 1). This paper posits that while using ICT by itself does not necessarily enhance critical thinking skills, if well-planned and implemented, ICT has great potential to enhance students' critical thinking and deep learning (Kivunja, 2013b). For ICT to fulfill this potential we need to articulate to our students exactly which thinking skills they are being taught using ICT and those skills need to be explicitly developed, modeled and repeatedly applied. This way, our students will develop an understanding that ICT is a mind tool, a support and resource for active dialoguing and learning, rather than just social media conversational tools. To demonstrate how this can be achieved, this paper uses the example of Gardner's bodily-kinesthetic MI to illustrate how trainee-teachers and those already in the profession, can apply some of the latest technological tools to mobilize the MI of Digital Natives endowed with the bodily-kinesthetic MI to help them enhance their critical thinking and to achieve their personal bests in the classroom. Before demonstrating that application, it is helpful to briefly explain in the following two sections, the meaning of critical thinking and what it involves, and to highlight what is meant by the term Digital Natives, as used in this paper.

\section{Critical Thinking}

\subsection{The Concept of Critical Thinking}

Critical thinking is the cognitive process that creates the ability to interpret, analyze and evaluate information, arguments or experiences with a set of reflective attitudes, skills and abilities to guide our thoughts, beliefs and actions. Dobozy, Bryer and Smith (2012) define it as "being able to tell facts from opinions, to see holes in an argument, to spot illogic, to evaluate evidence and to tell whether cause and effect have been established” (p. 4). Our students would not be engaged in critical thinking if they took what we tell them as gospel truth without questioning. Critical thinking requires that what is said is challenged and evaluated for its integrity and authenticity based on what is already known or available evidence. If there is not enough evidence to support what is said, then critical thinking would dismiss it as generally untrue. As Halpern (2003) explains, it is not critical thinking if we base our understanding on common sense and personal opinions. These are subjective ways of knowing whereas what is required in critical thinking is to identify objective data that support an observation or phenomenon, weigh the data from triangulated points of view and derive an informed way of knowing. In Larrivee (2008) we add to our understanding of critical thinking when we read that it helps us to dig deeper than the surface of ideas by putting them to objective test and asking why so as to develop deeper insights.

\subsection{Critical Thinking Attributes}

In discussing how we can encourage our students to be critical thinkers in the $21^{\text {st }}$ century, Trilling and Fadel (2009) suggest several attributes for critical thinking and problem solving. The first of these is the ability to reason effectively. This involves examining data or a situation and engaging in inductive or deductive reasoning to gain a deep understanding of the issue. The second attribute is the use of system thinking. This requires an analysis of how parts of a whole work together or interact among themselves so as to function as a cohesive whole. Next is the ability to make rational judgments and decisions. This is the ability not only to analyze but to also evaluate available evidence, arguments given and claims made. The analysis provides for looking at the data 
from different lenses and then making connections between and among the bits observed using what Professor Senge (1999) calls "Mental Models in Systems Thinking” (p. 8). From the analysis emerges interpretation of the data leading to data-based conclusions. The critical thinking process does not stop when conclusions are reached. Rather it continues so that reflection can take place to determine what learning has occurred. Ability to solve problems is the final attribute that Trilling and Fadel (2009) propose. The reason we should teach our teacher trainees critical thinking is so that they too should go on, after graduation, and teach it to their children because we believe that it enables students to think logically and deeply and to solve nonfamiliar problems in different ways.

\subsection{The Critical Thinking Process}

For students to learn critical thinking, they need to be explicitly taught the skills involved. They need to learn the process as well as the content of critical thinking. The process involves a deliberate attempt to acquire information and knowledge, staying focused, recognizing different alternatives and being prepared to evaluate the alternatives. It involves learners taking a position they can support with reasonable arguments, seeking precision in argumentation, proceeding with analysis in a logical and orderly manner and listening well so as to be sensitive to other peoples' positions (Facione, 2011).

Critical thinking doesn't just happen. As Pohl (1997) advises, it needs to be taught and developed through training in metacognition which leads to consciously asking questions about observations or ideas about personal thinking. As a way of such training, students should be encouraged to look for gaps in whatever information they are given and to then seek ways in which these gaps can be filled in. Students should be taught how to distinguish between straight forward observation and inference and between fact and conjecture or fiction. Critical thinking helps students recognize that words are mere symbols for ideas and not ideas themselves (Miller, 1990). As a way of training our students to learn critical thinking we should encourage them to probe for the assumptions that underlie what we teach them so that they can develop a fuller understanding of what we teach them and be able to draw inferences and conclusions from it. It is through teaching them how to develop hypothetical, deductive reasoning that we can help them to think deeply about relationships such as cause and effect and how they can be conscious of their own reasoning and test whether it is supportable with evidence or not, and whether it is generalisable or unique and specific (Mulnix, 2010).

The process of developing critical thinking involves many steps. Summarized from several authors (Facione, 2011; Miller, 1990; Mulnix, 2010), these steps include:

- Identifying key definitions;

- Identifying ambiguities that need to be clarified;

- Identifying key variables;

- Formulating relevant questions;

- Defining the issue or problem to be addressed;

- Classifying information;

- Sequencing information, recognizing patterns, determining credibility;

- Distinguishing fact from opinion;

- Identifying the underlying assumptions;

- Identifying values;

- Noting missing evidence;

- Identifying relationships through comparisons, contrasts and cause and effect, summarizing information, using analogies;

- Predicting trends from data;

- Predicting outcomes based upon evidence;

- Translating between verbal and symbolic events;

- Identifying conclusions, identifying errors in reasoning involving logical fallacies or statistical errors.

\section{Developing Critical Thinking among Digital Natives}

\subsection{Perceptions of Digital Natives}

The term "Digital Natives" is attributed to Prensky (2001) who defined it to mean children born after 1980 and 
have thus grown up into a world surrounded by computers, videogames, digital music players, video cams, cell phones, smart phones and all the new technological gadgets that crowd the digital landscape of the $21^{\text {st }}$ century. There is the perception that such children spend most of their time on computers, but especially on their smart phones, texting their peers, sending instant messages, chatting on Facebook, Twitter and MySpace, and sending their images using Instagram, playing Playstation and Xbox games or generally inquisitive as they explore the Internet (Jukes, McCain, \& Crockett, 2010).

There is also the understanding that the Digital Natives "are growing up digitally enhanced, [and that] because they have grown up in a digital environment, ... their brains have and continue to change physically and chemically, and are actually neurologically wired differently than our generation” (Jukes, McCain, \& Crockett, 2010: p. 19). These children, for example, tend to scan digital content and zero in on hot spots on web pages rather than read textual content.

In what he calls "Characteristics of the Net Geners" Tapscott (2009), discusses some eight characteristics that he regards as the norm of Digital Natives. These include expectation of freedom to a greater degree than earlier generations, customization of the digital technologies and services to their personal specifications (such as using iTouch to give their smart phones special features and downloading specific widgets and ring tones). They are also skeptical so that they tend to scrutinize whatever they scan on their technological platforms while online and scrutinize products deeply before they buy them or download apps lest they get their platforms bombed. Tapscott (2009) says "they have integrity and [therefore] care about being honest, considerate, transparent and abiding to their commitments" (p. 82). They are eager to collaborate and do so a lot through "digital zones” (p. 89). They have "borderless spheres of life and surf these in their high-tech world" (p. 91). "They expect speed and instant responses 24/7" (p. 93) and they live in a culture of innovation where technologies are emerging ever so often. As a result, they appreciate the rapid shift from a simple mobile phone to an iPhone, Android, Ipad or iPod and similar microtechnological technologies.

Given such a wide ranging array of perceived characteristics of Digital Natives, some apparently positive and others not so positive in influencing the thinking, activities and life styles of these children, debate has ensued as to whether the microtechnological tools in today's digital landscape enhance critical thinking of Digital Natives or not. Vigorous debate is welcome. It is a foundational attribute of critical thinking and so it should be encouraged. This author takes the philosophical stance that we, as higher education educators, need to teach our students so as to help them develop a balance between orthodoxy and digital pedagogical approaches to the development of critical thinking so that on graduation they will in turn be able to encourage their digital children to utilize digital tools in the active construction of knowledge.

\subsection{Discussion of Intriguing Examples}

In the postmillennial online environment, students have access to a wide array of powerful digital technologies which we can use to help them develop cognition as deep critical thinkers rather than superficial surface thinkers. If properly selected and applied, ICT technologies have potential to help our students actively engage with their learning, search for and access information, store it, create new information and use it to support critical thinking. In this section, I refer to apps assembled by Lustenhouwer (2012) and generously made accessible on the web without charge, to demonstrate how we can use selected digital technologies to develop critical thinking skills among Digital Natives, particularly endowed with Gardner's bodily-kinesthetic MI as defined earlier. Lustenhouwer has ingeniously assembled apps for eight of Gardner's MIs, and of course, there are many alternative apps, such as those developed by Schrock (2012) and Buckland (2014), but for the purposes of this paper, I have chosen to use only Lustenhouwer's apps and for only one MI for simplicity and illustrative purposes. The examples of utilizing Lustenhouwer's bodily-kinesthetic intelligence apps are illustrated in Figure 1 and discussed below with frequent reference to this figure.

Thanks to Lustenhouwer's work at http://ipadders.eu/apps-for-multiple-intelligences/, Figure 1 comprises eight icons each of which is a click-on active app which can be used not only to arouse students' interest and motivation, but provide great engagement, exploration, elaboration, evaluation and extension (Bruner, 1966) of knowledge to help students develop their critical thinking using their bodily-kinesthetic MI. This is a great tool that can give the bodily-kinesthetic students a hands-on experience which utilizes their MI strength to help them learn. 


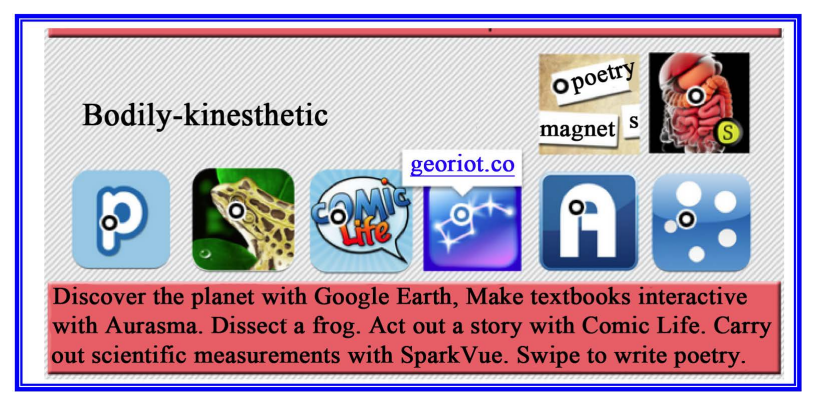

Figure 1. Digital apps to enhance critical thinking using bodilykinesthetic MI. Source: ippaders.eu.appsfor multiple intelligences: http://ipadders.eu/apps-for-multiple-intelligences/.

\subsubsection{The Popplet App}

The first of these apps looking like letter [P] is called a Popplet and is a great app for smart phones but particularly synchronized for the iPhone and iPad. When activated, the Popplet provides a very simple platform for students to create mindmaps of their thinking, or a cloud of ideas about the topic they are investigating. Students can work with it as a cooperative learning group and record their collective thinking and contribution to the topic. The versatility of the app enables students not only to brainstorm and explore ideas among themselves but to also represent those ideas as diagrams, charts or even outlines of complete projects they want to work on since they are kinesthetic MI inclined. Because the working platform expands as students add ideas to their thinking, project or notes, the Popplet is a great tool to challenge students endowed with the bodily-kinesthetic MI (Chapman, 1999) to explore new ways of thinking, creating and presenting their creations, creating galleries of photos they take with their iPhones or iPads, sort them into albums, send these to their friends or make presentations for whole class discussion. This capacity encourages students to engage in higher order thinking (Bloom, 1956) and to develop deep learning through critical thinking. The Popplet has many functionalities suited to the learning style of the bodily-kinesthetic learners, including Boundless Boards, Pan and Zoom, Realtime Collaboration, External VGA Display Support, Multi Language Support and PDF and JPEG Export options. With these hands-on technologies it is easy to see how it can be used in the classroom to train students in critical thinking particularly those endowed in bodily-kinesthetic MI as defined earlier.

\subsubsection{The Frog App}

The second app shown in Figure 1 is called Frog for obvious reasons and is most appropriate to be used in the study of organs and life systems of a frog. It is difficult to imagine a more exciting way, of cutting up a frog and revealing all its internal organs without killing the frog and without blood, guts and uric acid around. What could be more environmentally friendly for bodily kinesthetic primary school children to download the frog on their computer or smart phone and start dissecting it. As the bodily-kinesthetic MI children by definition want to work with their hands (Boggerman, Hoerr, \& Wallach, 1998), this is a great app, not only to teach them how to find and explore the internal organs of the frog, but to go on and investigate the function of each and how they all function together as a system that gives life to the frog. The use of such an app dispels the myth that such technologies provide click-click surface learning without deep understanding. When students working with this app are guided well by their teacher, students learn how to use all the tools that are needed to dissect the frog, actually dissect the frog and spread it out with vivid 3D images that give them opportunity to explore deeply the internal organs. They can then investigate how these organs function in harmony to create an equilibrium of metabolic processes that comprise a living frog.

This app is a great tool for the teacher too because it comes with detailed instructions that are textual visuals with sound as well as detailed information on each of the organs the students discover in the frog's body. This is a journey of discovery for the students and whether they are middle school or high school depending on their curriculum, the potential for captivating their interest, curiosity and motivation is great. The teacher can use it to extend the students because the app has an option to compare the anatomy of a frog with that of a human being. Such comparisons call for critical thinking at higher order thinking levels. The app even has a pre-designed short answer quiz on frogs; thus saving the teacher from the need to design a revision quiz for the class. 


\subsubsection{The Comic Life App}

The third icon app shown in Figure 1 is the Comic Life; an app that bodily-kinesthetic students will find hard to take their hands off because of its ability to create dynamic and vibrant images and comics that can be funny and intriguing. With it, children with kinesthetic dexterity (McGrath \& Noble, 2005) can create speech balloons, design photo images and photo filters, fancy letter fonts and designs, all sorts of shapes, shadows and effects. And all this can be done not necessarily on a computer but by simply clicking and tapping on an iPhone, iPod or iPad. The visual images are so cute this app would probably be so effective in teaching critical thinking to children with Gardner's Visual MI as well. Its capacity to engage children deeply is immense and this is reflected in its designers' assertion that "Comic Life, the award winning photo comic software is the funniest, easiest and fastest way ever to create photo comics on a mobile device" (http://ipadders.eu/apps-for-multiple-intelligences/).

Working with a variety of fonts on a laptop, notebook or desktop computer is no longer a novelty. But Comic Life puts novelty into font use when it makes more than sixty font options available on a smart phone. Its versatility allows children on a school excursion, for example, to take photos with their smart phone and instantly add them to their photo comic, and as one page fills up with images, they can simply click or scroll forward to the next page. This app encourages children to engage in deep critical thinking because it gives them opportunities to think about how they can edit the images they have assembled or accessed into comics of their own design. Having created the comics in their privacy, without the embarrassment of the images before they are designed to student's personal best, they can then make them as colorful as they want, put captions or ballooning comments on some and decide which ones to share and with some of their peers as well as teacher. They can even produce hard copies for their assignments or posters to display in their learning area. And as though that is not enough engagement and extension of knowing, they can upload their comics to social media platforms such as Twitter, Facebook and Google Circles (Kivunja, 2015), and provoke feedback from their followers. This is not the stuff of superficial remembering or click-click and go by a Digital Native. It is how Digital Natives endowed with bodily-kinesthetic MI can use technological tools to reach higher-order thinking, and engage in critical thinking and problem solving at its best (Pithers \& Soden, 2000).

\subsubsection{The Star Walk App}

The fourth icon app in Figure 1, Star Walk, should really have been called "Dancing with the Stars" (excuse the pun but I hope the humor is relevant). For this is an app that has potential to enchant children of the bodily-kinesthetic MI orientation to go stargazing at the beauty that the global universe has to offer (Chapman, 1999). Accessed via Comet ISON in Google Search, Star Walk brings interactive astronomy to the Digital Native and gives them the opportunity to explore the universe to the extent they can stretch their own imagination. Its simplicity as described by its creator is simply amazing. For you can simply "launch the app and point your iPhone at the night sky, you'll see stars, planets, satellites, and constellations in their proper place from your location” (http://ipadders.eu/apps-for-multiple-intelligences/).

Following this claim children no longer need high powered telescopes to gaze and wonder at terrestrial bodies. They can do this with the TelRad companion of the Star Walk. Used properly as teaching tools, these attributes enable Star Walk to encourage bodily-kinesthetic students to want to know more; to venture out into the unknown planetarium and extend knowledge to something new that might be out there which they can locate and share with their Twitter, Instagram and Facebook communities.

\subsubsection{The Aurasma App}

The fifth app that Lustenhouwer has designed for use with the bodily-kinesthetic children is, as illustrated in Figure 1, Aurasma, obviously derived from the English word aura. In The Australian Concise Oxford Dictionary, Hughes, Michell and Ramson (1992: p. 68) define an aura as "a field of a supposed subtle, luminous emanation surrounding the body of a living creature". This app should fascinate children of the bodily-kinesthetic orientation because it enables them to create their own reality Aura and share it with whoever they want on the Internet. With it children can photograph their surroundings and bring them to life by adding interactive digital images and sounds.

Application of the app in teaching and learning can combine creative skills with decision-making skills and problem solving skills of the bodily-kinesthetic children (McGrath \& Noble, 2005). For example, children can stretch their imagination to conceptualize how a 3D dinosaur could be added to their street address or locale and design a card with their own Aura selected from thousands of digital animations in Aurasma and then decide to 
send it to a friend or friends. They can create their own videos, animate them with Aurasma and share them as they wish. Here again we find evidence of giving children the opportunity to maximize the use of their bodily-kinesthetic MI orientation through applying ICT apps creatively. It would appear that none of these aurial manipulations are simply surface click-click maneuvers on the iPhone without engaging the child in deep thinking and critical judgment of the composition that they want to represent their own Aura and what to do with the created product.

\subsubsection{The Build-a-Body App}

In bodily-kinesthetic app number two in Figure 1 we dissected a frog. Now with Build-a-Body app number six for the iPad, children are challenged to explore the physiology of their own bodies. For the bodily-kinesthetic children that are by nature inclined to be inquisitive about their bodies (Gardner, 1983), what a fantastic way to get them engaged in thinking inquisitively and critically about what their body consists of and then investigate more deeply what each organ comprises.

Rather than provide click-click, move on, non-thinking experiences, Build-a-Body brings to the classroom what Hutchison (2007) described as "seemingly divergent worlds of video games and education in a pedagogically sound way that turns playing — and studying — video games into an educational and thoughtful learning experience" (p. xxi). Build-a-Body enables kinesthetically inclined children to do this because the app presents to them a tray containing all the organs that constitute a human body. They are then challenged to select one organ at a time and locate it where it fits best to build the human body. To simplify this feat, they can start by building organic systems one by one and then assemble these in the functionally optimal location to "create" the complete human body. If dissecting a frog was simply interesting, Build-a-Body should be not only interesting and entertaining, but capable of inspiring the bodily-kinesthetic children to critically ask why certain organs of the body need to be located where they are, and what if they were not or missing and how they function and why? This is bringing Playstation 3 effects into the classroom and effectively embedding digital technologies in the normal lives of Digital Natives.

\subsubsection{The Poetry Magnets App}

Whether bodily-kinesthetic children want to play with Zombies, take on mythical or romantic, or diabolic, or religious imagery, create a poem or engage in innuendo, the Poetry Magnets iPad app number seven, in Figure 1 is the one to launch them on this trajectory of critical thinking. Using tiles, somewhat similar to those used on digital Scrabble, this app gives children the capacity to critically think about new words that can be added to a stanza of a poem started by one of their peers so that they can engage in collaborative learning and enhance deeper critical thinking through cooperative learning. This has great propensity to enhance quality learning because as said in Cohen, Manion, Morrison and Wyse (2010), "cooperative learning enables students to work together to accomplish a shared goal. ... it enables pupils to learn very effectively with collective reinforcementmore effectively than in individualistic and competitive reward situations. It is a win-win situation for all participants” (p. 194).

\subsubsection{The SPARKvue App}

The eighth app illustrated in Figure 1 and recommended for working with bodily-kinesthetic children is SPARKvue. This is for the aspirational scientists among the children. With it children can use their iPhone, iPod Touch or iPad to gather a lot of scientific sensor data for their science projects in physics, chemistry, biology, earth science and environmental science. This is done in a gaming environment which combines academic work with fun to perform and conduct simple statistical analysis of the data assembled. The analyzed data can be displayed in ways critically thought out including charts, graphs and digital variants. The products from this gaming learning can be sent to an ordinary computer via email for further analysis.

\section{Conclusions}

Granted, not all learned scholars agree with Howard Gardner's regimen of MIs, which started off in 1983 as six and then became eight with the addition of the Naturalist MI, and now total to nine with the discovery of the Existential MI, which Gardner (2006) describes a "the intelligence of the big questions: Why do we live? Why do we die? Where do we come from? What is going to happen to us?” (p. 20). In Howard Gardner under Fire, 
for example, White (2006) refers to Gardner's MIs rather denigratingly as “Invalidities” and asks whether really "MI theory holds water" (p. 45). Similarly, it could be said that not every pedagogue agrees that the latest technological devices frequented by Digital Natives can enhance deep learning in pedagogical contexts. But these debates are in themselves a reflection of healthy critical thinking and its application by pedagogues in democratic economies, and should be encouraged.

As a higher education provider, this author believes and shares his pedagogical faith with his pre-service teachers, that Gardner's MIs are real and that our understanding of them should enable us to facilitate our students' learning by targeting their individual learning styles and strengths. As Gardner says:

Since human beings have their own unique configurations of intelligences, we should take that into consideration when teaching, mentoring, or nurturing. As much as possible, we should teach individuals in ways they can learn and we should assess them in a way that allows them to show what they have understood and to apply their knowledge and skills in unfamiliar contexts (Gardner, 2013: p. 3)

And as demonstrated in Kivunja (2013a, 2015) cutting-edge technological tools appear to have tremendous capacity to enhance active learning if well planned and carefully implemented. It is argued here that such capacity is yet to be fully understood and appreciated, let alone applied. Other scholars, such as Van Gelder (2001) are of a similar opinion.

This paper has endeavored to demonstrate how some of the latest fascinating apps could be used to help children of the bodily-kinesthetic orientation engage deeply in a fun-filled gamified but pedagogical way, in critical thinking at higher order levels of cognition, using carefully designed apps. It is a real credit to Lustenhouwer (2012) for her ingenious insights and pioneering research in this area, to come up with such fascinating tools that have potential for significant pedagogical impacts.

Prensky (2010) has alluded to the paradox that while technological innovations have been embraced by the Digital Natives this has been mainly for education everywhere else but the classroom. These words of wisdom should alert all of us engaged in higher education to the responsibility we have to train teachers that will be able to move these technologies from the world outside the classroom to become the favored pedagogical tools inside classrooms to enhance quality learning through critical thinking rather simply conversational media unrelated to academic pursuit.

The tsunami of technological innovations that have flooded the digital landscape needs to be given a surge so that carefully selected new technologies are quickly embedded in our pedagogical practices. Such embedment is needed to bring about a paradigm shift in the way we think and teach, so that on graduation, our graduates will be equipped with the skills they need to be productive and successful citizens in the $21^{\text {st }}$ century Digital Economy. This shift is so significant in pedagogy that Kivunja (2014) calls it "the New Learning Paradigm” (p. 85). It should enable us to move from teaching school skills that require students to cram vast quantities of information into their minds and memorization of content simply to impress us that they can recall so we give them marks, to microelectronics skills that will enable Digital Natives to develop capacity to become productive citizens that will be able to perform tasks relevant in the $21^{\text {st }}$ century digital world. This paradigm shift will see the demise of the stand and deliver teaching style and its rapid replacement with teaching strategies that say, get your smart phone out, or iPhone or iPad or iTouch, and click on this URL so that together we can investigate deeply the meaning of this concept, idea or data. This paradigm shift is long overdue. We owe it to our future teachers and the Digital Natives that they will teach, to embrace it without further delay. Moreover, the longer this paradigm shift takes to occur, the sooner lecture halls and classrooms, lecturers and teachers, will become irrelevant in the daily lives of Digital Natives.

\section{References}

Bloom, B. H. (1956). Taxonomy of Educational Objectives, Handbook 1: Cognitive Domain. New York: David Mackay Co.

Boggerman, S., Hoerr, T., \& Wallach, C. (1998). Succeeding with Multiple Intelligences: Teaching through the Personal Intelligences. Melbourne: Hawker Brownlow Education.

Bruner, J. S. (1966). Toward a Theory of Instruction. Cambridge: Harvard University Press.

Buckland, L. (2014). Multiple intelligences Infographics. https://www.pinterest.com/lianebuckland/multiple-intelligences

Cassidy, S. (2004). Learning Styles: An Overview of Theories, Models, and Measures, Educational Psychology, 24, 420-444. http://dx.doi.org/10.1080/0144341042000228834 
Chapman, C. (1999). If the Shoe Fits: How to Develop Multiple Intelligences in the Classroom. Melbourne: Hawker Brownlow Education.

Christensen, C. M. (2011). Disrupting Class: How Disruptive Innovation Will Change the Way the World Learns. New York: McGraw Hill.

Cohen, L., Manion, L., Morrison, K., \& Wyse, D. (2010). A Guide to Teaching Practice. New York: Routledge.

Dobozy, O., Bryer, B. \& Smith, R. (2012). Educational Psychology. Milton, Qld: John Wiley.

Dunn, R., \& Dunn, K. (1978). Teaching Students through Their Individual Learning Styles. Reston, VA: Reston.

Entwistle, N. (1981). Styles of Learning and Teaching. New York: John Wiley \& Sons.

Facione, P. A. (2011). Measured Reasons and Critical Thinking. Lillbrae, CA: The California Academic Press.

Gardner, H. (1983). Frames of Mind: The Theory of Multiple Intelligences. New York: Basics Books.

Gardner, H. (1999). Intelligence Reframed: Multiple Intelligences for the 21st Century. New York: Basic Books.

Gardner, H. (2006). Multiple Intelligences. New York: Basic Books.

Gardner, J. (2013). Assessment and Learning (2nd ed.). London: Sage.

Goleman, D. (2006). Social Intelligence: The New Science of Human Relationships. New York: Bantam.

Halpern, D. (2003). Thought and Knowledge (4th ed.). Mahwah, NJ: Lawrence Erbaum.

Hartman, V. F. (1995). Technical and Learning Style Preferences: Transitions through Technology. VCCA Journal, 9, 18-20.

Honey, P., \& Mumford, A. (1982). The Manual of Learning Styles. Maidenhead: Peter Honey.

Hughes, J. M., Michell, P. A., \& Ramson, W. S. (1992). The Australian Concise Oxford Dictionary. Melbourne: Oxford University Press.

Hutchison, D. (2007). Playing to Learn: Video Games in the Classroom. Westport, CT: Teacher Ideas Press.

Jukes, I., McCain, T., \& Crockett, L. (2010). Understanding the Digital Generation: Teaching and Learning in the New Digital Landscape. Melbourne: Hawker Brownlow Education.

Kivunja, C. (2013a). Application of Cutting-Edge Social Media Technologies in Constructionist Pedagogy. 3rd International Conference on Humanities, Geography and Economics (ICHGE'2013), within the 3rd International Conference on Economics, Humanities, Bio-Technology \& Environment Engineering (ICEHBEE'2013), Bali, 4-5 January, 2013, 115-120.

Kivunja, C. (2013b). Embedding Digital Pedagogy in Pre-Service Higher Education to Better Prepare Teachers for the Digital Generation. International Journal of Higher Education, 2, 131-142. http://dx.doi.org/10.5430/ijhe.v2n4p131

Kivunja, C. (2014). Do You Want Your Students to Be Job-Ready with 21st Century Skills? Change Pedagogies: A Paradigm Shift from Vygotskyian Social Constructivism to Critical Thinking, Problem Solving and Siemens' Digital Connectivism. International Journal of Higher Education, 3, 81-91. http://dx.doi.org/10.5430/ijhe.v3n3p81

Kivunja, C. (2015). Innovative Methodologies for 21st Century Learning, Teaching and Assessment: A Convenience Sampling Investigation into the Use of Social Media Technologies in Higher Education. International Journal of Higher Education, 4, 1-26. http://dx.doi.org/10.5430/ijhe.v4n2p1

Larrivee, B. (2008). Development of a Tool to Assess Teachers' Level of Reflective Practice. Reflective Practice, 9, 341-360. http://dx.doi.org/10.1080/14623940802207451

Lustenhouwer, S. (2012). Apps for Multiple Intelligences. http://www.ipadders.eu/apps-for-multiple-intelligences/

McGrath, H., \& Noble, T. (2005). Eight Ways at Once: Multiple Intelligences + Revised Bloom's Taxonomy = 200 Differentiated Classroom Strategies. Frenchs Forest: Pearson Education Australia.

Miller, S. (1990). Critical Thinking in Classroom Discussion of Texts: An Ethnographic Perspective. Paper No. ED320886, Boston, MA: American Education Research Association.

Mulnix, J. W. (2010). Thinking Critically about Critical Thinking. Educational Philosophy and Theory, 10, 471.

Pithers, R. T., \& Soden, R. (2000). Critical Thinking in Education: A Review. Educational Research, 42, 237-249. http://dx.doi.org/10.1080/001318800440579

Pohl, M. (1997). Teaching Thinking Skills in the Primary Years: A Whole School Approach. Melbourne: Hawker Brownlow Education.

Prensky, M. (2001). Digital Natives, Digital Immigrants Part 2: Do They Really Think Differently? On the Horizon, 9, 1-6. http://dx.doi.org/10.1108/10748120110424843

Prensky, M. (2010). Understanding the Digital Generation. Moorabin: Hawker Brownlow Education.

Schaler, J. A. (Ed.) (2006). Howard Gardner under Fire: The Rebel Psychologist Faces His Critics. Chicago, IL: Open Court.

Schrock, K. (2012). Bloom’s Revised Taxonomy. http://www.schrockguide.net/bloomin-apps.html 
Senge, P. (1999). The Fifth Disciple: The Art and Practice of the Learning Organization. Adelaide: Griffin Press.

Sternberg, R. J. (1985). Beyond IQ: A Triarchic Theory of Human Intelligence. New York: Cambridge University Press.

Tapscott, D. (2009). Grown up Digital: How the Net Generation Is Changing the World. New York: McGraw Hill.

Trilling, B., \& Fadel, C. (2009). 21st Century Skills: Learning for Life in Our Times. San Francisco, CA: Jossey-Bass.

Van Gelder, T. (2001). How to Improve Critical Thinking Using Educational Technology. In Meeting at the Crossroads (pp. 539-548). Melbourne: The University Melbourne, Department of Philosophy.

Wegerif, R. (2002). Thinking Skills, Technology and Learning. Bristol: Futurelab Report 2.

White, J. (2006). Multiple Invalidities. In J. A. Schaler (Ed.), Howard Gardner under Fire (Ch. 3, pp. 45-71). Illinois: Open Court. 